\title{
Despindo preconceitos: (re)conhecendo os movimentos sociais no Brasil através de suas lutas pela reforma agrária
}

\author{
Undoing prejudice: (re)cognizing social movements in Brazil through their struggles for \\ agrarian reform
}

\author{
Caroline Michely da Silva ${ }^{1}$ \\ Daniela Resende Archanjo ${ }^{2}$
}

\begin{abstract}
Resumo
Este artigo aborda a histórica luta e resistência de movimentos sociais pela reforma agrária no Brasil e a recente renovação da luta por sistemas alimentares mais justos. Aponta a emergente necessidade de despir preconceitos, ampliar e fortalecer o debate sobre os conflitos e disputas de interesses no campo da segurança alimentar no Brasil, visto que a lógica colonizadora do sistema alimentar globalizado tem sido fundamentada, até mesmo legitimada, pela visão economicista de determinados grupos - que exercem poder e influência política na regulação da economia e das políticas públicas do Brasil. Através da pesquisa bibliográfica e de documentários, o trabalho discorre sobre a difusão tecnológica na agricultura; a dinâmica mercantil do agronegócio; e os diferentes mecanismos criados na relação de poder político-empresário, para dominação e repressão dos movimentos sociais. Assim, este ensaio analítico visa dar visibilidade ao tema, contribuindo para o (re)conhecimento e fortalecimento destes movimentos populares sob a perspectiva epistemológica da decolonialidade. Destacamos como "as novas/ velhas" formas de controle e dominação de caráter colonial mantém não só a estrutura fundiária, a repressão violenta aos que lutam; mas, também, a "imagem negativa" de alguns movimentos sociais perante o restante da sociedade - tendo o caso do Movimento dos Trabalhadores Rurais sem Terra (MST) como exemplo neste debate. E, enfim, apontamos a necessidade de conectar o que a ciência tem avançado sobre a agroecologia e a biotecnologia, com o conhecimento adquirido pela população através do tempo e de experiências atuais no campo da agricultura/alimentação.
\end{abstract}

Palavras-chaves: Soberania Alimentar. Movimentos Sociais. Agronegócio. Decolonialidade.

\begin{abstract}
This article discusses the historical struggle and resistance of social movements for agrarian reform in Brazil and the recent renewal of the struggle for fairer food systems. Points out the emerging need to disregard prejudices, broaden and strengthen the debate about conflicts and disputes of interests in the field of food security in Brazil, since the colonizing logic of the globalized food system has been justified, even legitimized, by the economistic view of certain groups that exercise power and political influence in the regulation of Brazil's economy and public policies. Through bibliographical research and documentaries, the work deals with the diffusion of technology in agriculture; the mercantile dynamics of agribusiness; and the different mechanisms created in the State-Market relationship, for domination and repression of social movements. Thus, this analytical essay aims to give visibility to the theme, contributing to the (re) knowledge and strengthening of these popular movements under the epistemological perspective of decoloniality. We emphasize how the "new / old" forms of control

\footnotetext{
${ }^{1}$ Mestre em Desenvolvimento Territorial Sustentável pela Universidade Federal do Paraná (UFPR). Assistente Social da Prefeitura Municipal de Itapoá/SC. E-mail: caroline_michely@ hotmail.com

${ }^{2}$ Doutora em História (UFPR). Professora do curso de Administração Pública do Setor Litoral da UFPR. E-mail: danielaarchanjoufpr@gmail.com
} 
and domination of colonial character maintains not only the land structure, the violent repression of those who fight; but also the "negative image" of some social movements vis-à-vis the rest of society - with the Movimento dos Trabalhadores Rurais sem Terra (MST) as an example in this debate. And, finally, we point out the need to connect what science has advanced on agroecology and biotechnology, with the knowledge acquired by the population through time and current experiences in the field of agriculture / food.

Keywords: Food Sovereignty. Social movements. Agribusiness. Decoloniality.

\section{Introdução}

Assistimos a um cenário altamente vulnerável do sistema alimentar globalizado e das políticas de segurança alimentar no Brasil. O campo da alimentação está em crise. Se, por um lado, o agrobusiness é importante para a segurança econômica do Brasil ${ }^{3}$, por outro lado representa a insegurança alimentar da população. Estamos ameaçados pela gradativa contaminação da água, do solo e dos alimentos, além de convivermos com o fato de que uma considerável parcela da população tem dificuldade para acessar/consumir alimentos de qualidade e em quantidade suficiente.

É notável a disputa ideológica e, consequentemente, sociopolítica, no campo da alimentação. No Brasil, enquanto a emissora de televisão Rede Globo ${ }^{4}$ faz campanhas exaltando o agronegócio como "a solução" para o país, usando slogans como "agro é pop, agro é tech, agro é tudo", muitos problemas gerados pela intensa industrialização do campo e mercantilização do alimento são escondidos. Mas não sem resistência. Existem movimentos sociais que lutam contra o sistema alimentar globalizado. Historicamente estes povos sentem "na carne" a privação de alimentar-se adequadamente, ou a dificuldade de acessar a terra para produção, além dos que adoecem com a intoxicação dos agroquímicos. Sentem a perda cultural, dos costumes e modos de vida ligados à agricultura camponesa.

O trabalho discorre sobre a dinâmica mercantil do agronegócio, ou agrobusiness, as intenções por trás da Revolução Verde, que estão ligadas ao desejo do capitalismo de controlar o sistema alimentar globalizado. Neste contexto, reconhecemos que a alimentação é um campo de lutas: enquanto o império alimentar tenta expandir territórios, povos tradicionais e movimentos sociais tentam resistir às investidas do agronegócio, visando a autonomia alimentar; a disputa é,

\footnotetext{
${ }^{3}$ Estudos econômicos apontam a agropecuária como o setor que registrou a maior taxa de crescimento nas pesquisas do IBGE, nos últimos dois anos, inserindo o agronegócio no patamar de o principal setor que fez a economia crescer em 2017 (SERIGATI, et. al, 2017).

${ }^{4}$ Ressalta-se que a Rede Globo (Globo Comunicação e Participações S/A) é sócia da Associação Brasileira do Agronegócio (ABAG), ver em: http://www.abag.com.br/institucional/associados.
} 
essencialmente, ideológica e política, pois a ideologia economicista (aparentemente hegemônica) trata estes movimentos e suas experiências com violenta repressão e inferioridade perante aos imperativos do sistema econômico global, o que demonstra a necessidade de ampliar e fortalecer este debate na comunidade acadêmica.

Destarte, o presente trabalho pretende ser apenas uma contribuição - até mesmo provocação - a um debate que é emergente e que precisa ser despido de preconceitos, sobre a histórica e atual luta e resistência de movimentos sociais por sistemas alimentares mais justos. Assim, este ensaio analítico visa dar visibilidade ao tema, contribuindo para o fortalecimento/reconhecimento destes movimentos populares sob a perspectiva epistemológica da decolonialidade.

Com base em referências bibliográficas, a primeira seção apresenta a ideologia economicista que impulsionou a difusão da tecnologia na agricultura e que alimenta o agronegócio, bem como algumas relações sócio-históricas e contemporâneas no campo da política em relação à questão agrária no Brasil. Na segunda seção destaca-se a crítica ao modelo hegemônico de desenvolvimento, que consolida o império alimentar e inferioriza o campesinato e suas lutas que reivindicam sistemas alimentares mais justos. Apresentamos o modelo de pensamento decolonial, que visa uma mudança de paradigma nas concepções da ciência e da sociedade, sobre os movimentos sociais e a complementaridade entre a ciência e a sabedoria popular.

$\mathrm{Na}$ terceira, e última seção, como base utilizamos alguns documentários, além da revisão bibliográfica, para abordar a luta pela reforma agrária no Brasil, a partir da narrativa da história de pessoas ligadas ao movimento Ligas Camponesas e ao Movimento dos Trabalhadores Rurais sem Terra (MST), a fim de ilustrar: como os conflitos e disputas de interesses marcaram e mantém as injustiças da questão agrária, ou melhor dizer, questão latifundiária do Brasil; e os mecanismos de dominação e repressão do Estado sobre os movimentos sociais que reivindicam direitos e justiça no campo.

\section{A visão economicista: "do que o agronegócio se alimenta"}

Importante esclarecer que neste estudo o sistema alimentar globalizado corresponde ao conjunto de regras e relações que regulam os processos de produção, beneficiamento, industrialização, distribuição e acesso aos alimentos em escala mundial. Neste sistema há uma influência importante do agrobusiness, ou agribusiness, ou agronegócio - que representa a totalidade 
das empresas e negócios que giram em torno da alimentação -, um grande negócio caracterizado pela produção em larga escala predominantemente exportadora, altamente mecanizada e monocultora.

Partindo de uma perspectiva histórica, a agricultura era genuinamente localizada, uma atividade econômica essencial em que cada território tinha seu próprio modo de produzir, distribuir e preparar alimentos. Ao longo do tempo tais modos tornaram-se tradição cultural, visto que para além da sobrevivência há o valor simbólico e ontológico das práticas alimentares. Posteriormente, a modernização da agricultura foi um fenômeno fortalecido com a chamada "Revolução Verde", no final da década de 1940, mobilizada por empresas, instituições científicas e líderes políticos. Estes atores fomentaram o chamado pacote tecnológico, que inclui: o melhoramento de sementes; o uso de agrotóxicos: herbicidas, inseticidas e fertilizantes químicos; e a construção e adoção de maquinários pesados: tratores, colheitadeiras, entre outros para serem utilizados desde o plantio até a colheita (ANDRADES; GANIMI, 2007).

O principal argumento para esta revolução na agricultura foi evitar uma crise de abastecimento de alimentos em escala global e exterminar a fome no mundo, sendo necessário aumentar a quantidade de produção de alimentos diante do intenso crescimento da população mundial. $O$ discurso a favor da Revolução Verde foi bastante conveniente na época, pois o fim da década de 1940 foi marcado pelo fim da Segunda Guerra Mundial, momento histórico em que o contexto social e político era de crise, em que a fome estava espalhada em diversos territórios do mundo.

Entretanto, autores apontam outras intencionalidades por traz destes pacotes tecnológicos. Segundo Capra (2002, p. 185), "estes planos, mais do que quaisquer outros, evidenciam a fria intenção comercial que está por trás da modificação genética de cereais e outros produtos agrícolas”. Neste sentido, Andrades e Ganimi (2007) demonstram que este processo de modernização representou a dominação capitalista da agricultura, que para além da mudança técnica, visa: “a maximização do lucro, através da monopolização de fatias cada vez maiores do mercado; e a aquisição de royalties, por intermédio dos pacotes tecnológicos. Assim criaria um círculo de dependência para o agricultor que só conseguiria os pacotes tecnológicos produzidos pelas transnacionais" (idem, p. 44).

Nesse sentido, Capra (2002) discorre sobre consequências importantes pós-Revolução Verde:

A Revolução Verde não ajudou nem os agricultores, nem a terra, nem os consumidores. $\mathrm{O}$ uso maciço de fertilizantes e pesticidas químicos mudou todo o modo de se fazer agricultura, na mesma medida em que as empresas agroquímicas convenceram os agricultores de que poderiam ganhar dinheiro plantando um único produto agrícola em áreas enormes (...). A prática da monocultura, além de acarretar o forte risco de que uma grande área plantada seja destruída por uma única praga, também afeta seriamente a saúde dos lavradores e das pessoas que moram nas 
regiões agrícolas. (...) a agricultura tornou-se mecanizada e passou a ser marcada pelo uso intensivo de energia, favorecendo assim os grandes fazendeiros e agroindústrias munidos de capital suficiente e expulsando da terra a maioria das famílias tradicionais de agricultores (CAPRA, 2012, p. 183).

Em síntese, a difusão da tecnologia na agricultura e na agropecuária acarretou importantes mudanças nos modos de produção, que foram gradativamente acolhidas pelos produtores em diversas áreas do mundo, tornando a produção de alimentos e de matéria-prima um importante negócio para o sistema econômico global.

O sistema de exportação de matéria-prima, principalmente os frutos da agricultura e da agropecuária, atualmente, são conhecidos como comodities - que correspondem aos produtos produzidos em larga escala, sob um sistema de preços determinados pela oferta e procura internacional.

Assim, a produção do campo mobiliza diversos setores da sociedade, e este sistema tem fortalecido a atuação dos atores privados na governança global do sistema alimentar. As grandes corporações, os produtores, processadores e varejistas de larga escala "estão cada vez mais dominando o mercado alimentício e determinando a formulação das regras da governança alimentar" (BRASIL, 2013, p. 52). Em 2013, as empresas multinacionais como a Monsanto, a Cargill, a Archer Daniels Midland, a Moisac, o Walmart e o Carrefour, controlavam pelo menos $25 \%$ do mercado global de sementes, pesticidas, fabricação e comercialização de alimentos no varejo, além da prática de lobby nos governos em definições de normas e regras, estas empresas influenciam instituições de pesquisas e difusão de conhecimento sobre a alimentação (BRASIL, 2013).

Para Ploeg (2008), este contexto representa um “império alimentar" estabelecido, trata-se do domínio das grandes corporações da lógica mercantil - do baixo custo de preços dos alimentos produzidos, processados e comercializados em larga escala. Em outras palavras, a dinâmica mercantil do agrobusiness controla o sistema alimentar globalizado, exercendo poder em escala global e local, nos territórios onde as empresas negociam.

No caso brasileiro, desde o Brasil-Colônia a elite rural exerce forte influência na política e na economia, em que a questão do latifúndio e impedimento de acesso a terra para determinados povos está profundamente enraizada na formação sócio-histórica do Brasil. Atualmente, ainda vemos uma estrutura fundiária preservada, assim como as ideologias que defendem que políticas de reforma agrária impossibilitam o progresso e "desenvolvimento" do país (BUAINIM; PIRES, 2003).

Destarte, a força da elite rural perpetua no Brasil, a exemplo disto, em 2017 a bancada ruralista representava $41 \%$ dos parlamentares da Câmara dos Deputados (O GLOBO, 2017). Historicamente, 
essa bancada é considerada umas das bancadas mais atuantes, principalmente, em favor do agronegócio (MEDEIROS; FONSECA, 2016).

Prestando um pouco mais de atenção à dinâmica das pautas e votações no Congresso Nacional, não é difícil perceber que, na prática, os votos dos parlamentares ruralistas são "negociados". O apoio ou não da bancada a determinadas propostas do governo ou de outras bancadas é usado como moeda de troca em prol da flexibilização da legislação afeta à segurança alimentar, ao meio ambiente e à questão latifundiária no país. Podemos citar como exemplo: a liberação de agrotóxicos, venda de terras para estrangeiros, regras para licenciamento ambiental, anistia de dívidas de latifundiários, etc.

Neste cenário tradicional de busca de votos, vale mencionar um episódio recente: a rejeição da Câmara dos Deputados para que as graves denúncias contra o então presidente, Michel Temer, seguissem para o Supremo Tribunal Federal (STF) em 2017. Os deputados que justificaram os votos, claramente, expressaram discursos progressistas e economicistas para o "bem" do país - fatos que foram noticiados na mídia nacional, demonstrando as barganhas utilizadas para favorecer o agronegócio no Brasil (SILVA, 2018). Em reportagem publicada em jornal de grande circulação no país, leu-se:

\begin{abstract}
Encurralado por denúncias de um lado e pedidos de impeachment de outro, o presidente Michel Temer intensificou a barganha entre governo e base aliada para garantir a própria blindagem no Congresso. No cenário de busca voto a voto, a agenda ambiental entrou para o centro das negociações como moeda de troca importante na conquista do apoio da bancada ruralista. (...) No balcão atual de negociações com o governo, estão propostas tão ou mais impactantes para a preservação da natureza, segundo especialistas, como a flexibilização de regras para licenciamento ambiental, liberação de agrotóxicos e venda de terras para estrangeiros. O governo prepara uma medida provisória sobre dívidas bilionárias de produtores ao Fundo de Assistência ao Trabalhador Rural (Funrural) sob a pressão de parlamentares ligados ao agronegócio, que pleiteiam anistia de multas, descontos e maior prazo para pagar (O GLOBO, 2017).
\end{abstract}

Outro peso, no que diz respeito ao agronegócio, são as tradicionais práticas de "doação" financeira por parte de empresas e de pessoas físicas para as campanhas eleitorais. Pesquisadores já apontam este sistema de "doação", sendo na realidade um financiamento, ou seja, a expectativa de retorno financeiro do valor investido (HOROCHOVSKI et al., 2015).

Como exemplo, nas eleições de 2014 as empresas JBS e Ambev, ambas do setor alimentício, estiveram dentre as três empresas que mais financiaram as campanhas políticas para presidência no país. No primeiro mês de campanha das Eleições de 2014, a JBS (das marcas Friboi, Seara, Doriana 
e outras) concentrou 35\% do total financiado aos três principais candidatos à presidência: Dilma Rousseff (PT), Aécio Neves (PSDB) e Eduardo Campos (PSB). Vale destacar que nos anos posteriores a JBS liderou rankings de rendimento e se tornou a maior empresa de carnes no mundo; e em 2017, foram noticiados os escândalos sobre o sistema milionário de corrupção envolvendo propinas e vantagens entre a JBS e políticos brasileiros (SILVA, 2018).

Porém, o discurso que alimenta o agronegócio e a necessidade de manter o equilíbrio da economia parte de estudos econômicos que demonstraram, por exemplo, que o ano de 2017 foi um dos melhores para o agronegócio brasileiro, devido à ótima safra de 2016/17. As projeções sugerem que o PIB das atividades agropecuárias cresceu 11,5\% neste ano - registrando a maior taxa de crescimento nas pesquisas do IBGE, inserindo o agronegócio no patamar de o principal setor que fez a economia crescer em 2017 (SERIGATI et. al., 2017).

Neste cenário, economistas e empresários defendem a potencialidade deste setor para a expansão do país na economia global, assim como para gerar renda, emprego e desenvolvimento, essenciais para a população brasileira. Em contrapartida, pesquisas sobre o mercado de trabalho demonstraram que a taxa de desemprego do primeiro trimestre de 2017 atingiu 13,7\% da população, indicando que mais de 14 milhões de pessoas estavam desocupadas (SERIGATI et. al., 2017).

Os fatos apresentados ilustram parte do peso econômico e das relações políticas entre EstadoMercado que afetam as disputas de interesses capitais sob o agronegócio e a segurança alimentar no Brasil. Analisando este cenário sob a perspectiva harveyniana, assim como ocorre com a economia global, assistimos ao agrobusiness avançar numa lógica territorial e capitalista de poder, através de uma tradição imperial, predatória e colonizadora (HARVEY, 2003).

A tradição imperial, abordada por Harvey (2003), está marcada na história latifundiária do país, perpetuando-se na contemporaneidade nas relações paternalistas e nos diversos mecanismos de poder. Ou seja, esta tradição está marcada na colonização moderna, que para além da economia (nas questões de acesso a terra e outros bens), também está presente no campo político, ideológico e cultural, conforme veremos a seguir.

\section{A visão decolonial: sentipensar sobre a luta de movimentos sociais}

Apresentamos, até o momento, a lógica colonizadora do sistema alimentar globalizado que tem sido fundamentada, até mesmo legitimada, pela visão economicista de determinados grupos, que exercem poder e influência política na regulação da economia e das políticas públicas do Brasil. Tal 
lógica está explícita: na perda da autonomia dos produtores, que estão dependentes do pacote tecnológico vendido pelas transnacionais (sementes, agrotóxicos e maquinários); na manutenção do latifúndio; nas relações políticas (busca de votos, financiamento de campanhas, etc.) que influem na regulação governamental em prol de interesses de empresas privadas, em detrimento de interesses sociais; na insegurança alimentar (da fome ao consumo excessivo de produtos alimentícios altamente processados e nocivos à saúde); entre outras situações.

Partindo do reconhecimento de que a visão economicista é unilateral e reducionista (KAPP, 1979), pois busca o crescimento econômico a qualquer custo, como se este modelo de “desenvolvimento" bastasse para suprir as demais necessidades da população e representasse a solução para os problemas sociais; autores latino-americanos têm apontado em seus estudos a importância dos movimentos sociais e de seus saberes (práticas e modos de vida) na resistência ao império capitalista.

De acordo com os estudos, a atitude imperial e as relações coloniais foram renovadas na modernidade, atuam em diversas dimensões da vida, e foram fundamentadas pelas concepções cartesianas de ideologia de raças, na visão dicotômica entre corpo/mente, homem/natureza e outras (MALDONADO-TORRES, 2003; LANDER, 2005; ESCOBAR, 2016).

A concepção cartesiana, de que o universo material era uma máquina, nada além de uma máquina, de que não havia propósito, vida ou espiritualidade na matéria, corroborou para ideia de que a natureza funcionava de acordo com leis mecânicas. A mesma linha de pensamento que envolve os princípios da mecânica newtoniana, marcando "a revolução científica que tratou de substituir a concepção orgânica da natureza pela metáfora do mundo como máquina” (CAPRA, 1981, p. 46).

Este modelo de pensamento ocidental impulsionou o sistema político-econômico da sociedade capitalista, ou seja, o conjunto de relações econômicas, políticas, culturais, enfim sociais, que compuseram a modernidade.

A dinâmica instituída, assim como suas formas de significar e categorizar a vida social, contribuiu não apenas para novos padrões e normas culturais, mas reforçou a divisão analítica entre sociedade e meio ambiente - tonificada pela tradicional divisão positivista adotada anos mais tarde. Como aponta Almeida Jr. (1994, p. 87), devemos ter em mente que essa visão de corpo interfere no comportamento dos agentes econômicos, “(...) orienta a ação dos empresários que devem lidar com seres vivos, como é o caso na agricultura e na pecuária, na indústria de alimentos, nas empresas de saúde (...)”. Sobretudo, estas concepções serviram como modelo para as bases da ciência, favorecendo o darwinismo sob a ideia de raças, como também a lógica de superioridade/inferioridade nas relações humanas. 
O debate sobre atitude imperial trata de uma categoria de pensamento cultural e política que serve à hierarquização e subjugação dos povos, legitimando mecanismos de domínio do império capitalista, ou do império alimentar. São ideologias que justificaram os genocídios e as atitudes violentas nos processos de colonização, e que na contemporaneidade classificam os países “desenvolvidos" como modelos a serem seguidos, em detrimento dos países "subdesenvolvidos" ou "em desenvolvimento" 5 .

Destarte, os estudos decoloniais visam à inversão desta lógica estabelecida pela ciência, com críticas ao controle dominante do sistema capitalista, reconhecendo as formas de colonialidade: do ser, do saber e do poder ${ }^{6}$; e valorizando os conhecimentos/saberes dos movimentos sociais e dos povos oprimidos, em suas lutas e resistências (MALDONADO-TORRES, 2003). Em suma, o debate sobre a perspectiva decolonial tem sido relevante para valorizar e dar visibilidade aos movimentos sociais, mas também para desmistificar ideologias eurocêntricas que inferiorizam os conhecimentos, modos de vida e práticas alternativas ao modelo de desenvolvimento dominante.

Os movimentos sociais têm histórias de lutas e resistência sobre diversas questões, sejam de raça, gênero, sexualidade, terras e território, modelos alternativos de desenvolvimento, autonomia alimentar, entre outras. No campo da alimentação, alguns movimentos sociais ampliaram o debate sobre o sistema alimentar globalizado, a exemplo disso, a Via Campesina tem contribuído significativamente para a defesa de sistemas alimentares mais justos.

Vía Campesina se ha revelado como un actor principal en las actuales luchas populares internacionales contra el neoliberalismo que, entre otras cosas, exigen responsabilidades a las agencias intergubernamentales, se enfrentan y se oponen al control corporativo sobre los recursos naturales y la tecnología, y defienden la soberanía alimentaria. Además, ha contado con un papel destacado en campañas de gran polémica política como, por ejemplo, las dirigidas contra la OMC, los gigantes corporativos mundiales como McDonalds, y los organismos modificados genéticamente $(\mathrm{OMG})$ y las multinacionales que los fomentan, como Monsanto (BORRAS, 2004, p. 3).

\footnotetext{
${ }^{5}$ Esta classificação tem como base um modelo de desenvolvimento hegemônico, que pauta-se no crescimento econômico como pilar para o desenvolvimento social de um país, com uma perspectiva unilateral. Porém, "desenvolvimento" é um conceito polissêmico e, longe de um consenso, há diferentes correntes teóricas que propõem seus próprios modelos de maneira bastante diversa, citamos como exemplos: ecodesenvolvimento, desenvolvimento sustentável, desenvolvimento territorial sustentável - são modelos com visões multilaterais e que possuem características plurais e radicalmente democráticas, como alternativas ao modelo hegemônico (SACHS, 2008; VIEIRA, 2006).

${ }^{6}$ Colonialidade do poder se refere a inter-relação entre formas modernas de exploração e dominação. Colonialidade do saber é o rol epistemológico e de produção de conhecimentos, os regimes de pensamentos coloniais que imperam (escolarização do saber). Colonialidade do ser então é a experiência vivida da colonização e seu impacto na linguagem trabalha a fenomenologia e a filosofia existencial, com perspectiva sobre a subalteridade racial e colonial (MALDONADO-TORRES, 2003).
} 
O conceito Soberania Alimentar é fruto deste movimento e surgiu como alternativa para o modelo de produção alimentar mecanizado, visando autonomia aos pequenos agricultores. Este conceito foi criado em 1996, e desde então foi acolhido pela ONU e tem ganhado espaço gradativamente na legislação brasileira e nas discussões públicas, sendo considerado um importante avanço para uma sociedade sustentável (PARANÁ, 2009).

Soberania Alimentar trata do direito dos povos ao acesso a alimentos saudáveis (livre de agrotóxicos) e culturalmente adequados, acessíveis, produzidos de forma sustentável e ecológica; e o direito de decidir seu próprio sistema alimentar e produtivo. Ou seja, trata de todo o ciclo da alimentação, o direito de produzir, transformar, consumir, importar e exportar alimentos sem reproduzir o modelo de produção imposto pelo capitalismo; em modelos de produção que sejam justos do ponto de vista social e ambiental. A realização da Soberania Alimentar implica na garantia das condições mínimas para a qualidade de vida humana e do meio ambiente, mesmo em situações de vulnerabilidade e independente de impactos de crise econômica, social ou ambiental.

Aos ceticistas pode parecer utópico, mas diversas experiências locais demonstram a viabilidade de sistemas alimentares mais justos. A noção ideológica de inferioridade sobre os movimentos e suas experiências demonstram a necessidade de ampliar e fortalecer este debate na comunidade acadêmica, bem como sua responsabilidade em desvelar histórias e conhecimentos adquiridos nestes processos de luta e resistência dos movimentos sociais.

A luta da Via Campesina frente à crise climática e alimentar é pela mudança do modo de produção convencional rumo ao sistema de produção agroecológica. A crítica parte dos modelos de extração e exploração do agronegócio (agroindústria, agropecuária e agrocombustível), legitimados como estratégia eficiente para o crescimento econômico.

Para Escobar (2015) as lutas demonstram os saberes produzidos pelos ativistas em defesa de territórios e mundo relacionais - muitas vezes subjugados pela ciência. Considera que os seres modernos, nós, perdemos nossa relação integrada com o universo e devemos restaurar nossa intimidade com a Terra. Saberes indígenas consideram que somos continuidade da Terra. Mas, o pensamento intelectual hegemônico tem hostilizado esta realidade.

O giro decolonial trata dessa mudança de paradigma nas concepções da ciência e da sociedade sobre os movimentos populares, remete ao valor do conceito de Sentipensar ${ }^{7}$ de Escobar (2015) e a necessidade de complementaridade entre ciência e sabedoria popular.

\footnotetext{
${ }^{7}$ Sentipensar é reconhecer nas histórias de luta a vasta manifestação ontológica dos povos em defesa da vida, suas relações com a terra, a natureza, de forma integrada ao universo e espiritualizada. Segundo Escobar (2015), "puesto que no podemos tener intimidad con la Tierra bajo un paradigma mecánico, necesitamos urgentemente una Nueva Historia que nos permita reconectar lo sagrado con el universo, lo humano y lo no-huma no. Las sabias tradiciones, que incluyen las
} 
O movimento conhecido como Epistemologias do Sul (ES) fornece ferramentas adequadas para aqueles que não querem mais ser cúmplices do silenciamento do conhecimento e das experiências populares, dominados pelo conhecimento eurocêntrico - a estrutura desta corrente teórica critica radicalmente categorias colonialistas que transfiguraram as experiências dos movimentos sociais, expressando-as como ilegíveis ou invisíveis (ESCOBAR, 2015).

À luz desta perspectiva epistemológica, apresentamos a seguir um breve relato histórico das experiências de alguns movimentos sociais que atuaram no Brasil, em questões da luta pela terra (Reforma Agrária) e por melhores condições de vida relacionadas à alimentação; ilustrando através da história as formas de subjugação e dominação de alguns movimentos do país.

\section{Sobre a história de alguns movimentos sociais do Brasil: "criminalizar é poder!"}

Para fazer uma breve apresentação dos processos sociais que envolveram a questão agrária no país nas últimas décadas, e ao mesmo tempo relacioná-los com a perspectiva decolonial, as histórias de luta dos movimentos sociais foram descritas a partir da revisão bibliográfica de diversos autores (OLIVEIRA, 2001; BRUMER; SANTOS, 2006; MOTTA; ESTEVES, 2009; ROCHA; BARBOSA JR., 2018), mas também das narrativas dos próprios membros de alguns dos movimentos que fizeram parte do movimento Ligas Camponesas - tendo como base alguns documentários ${ }^{8}$.

Ressalta-se que existiu, e ainda existem, diversos movimentos, associações, sindicatos, e outros tipos de organizações espalhadas no Brasil, porém devido a condição de tempo e espaço para a produção deste trabalho, optamos por descrever a história de dois movimentos sociais, talvez os mais polêmicos no país - sendo este o critério de escolha.

No Brasil, nas décadas de 1950 a 1960, o movimento social intitulado Ligas Camponesas travou uma importante luta contra o poder dos coronéis, reivindicando a reforma agrária no país. $\mathrm{O}$ movimento iniciou, em 1954, com um grupo de camponeses que procuraram o apoio de Francisco Julião, deputado estadual (de Pernambuco) e advogado, para formalizar uma associação mutualista. Julião, além de apoiar este grupo, passou a organizar outros grupos que enfrentavam a mesma situação na região de Pernambuco, agindo como defensor dos camponeses e "incendiando consciências" sobre as condições dos trabalhadores rurais naquele período.

\footnotetext{
de los pueblos indígenas, nos sirven como guía parcial hacia esa meta de reintegrarnos con la Tierra” (ESCOBAR, 2015, p. 27).

${ }^{8}$ Ver nas referências deste trabalho.
} 
A conjuntura específica daquela região de Pernambuco, porém não muito diferente das práticas realizadas em outros cantos do país, estava marcada pelo coronelismo, em que a maior parte das áreas (terras) eram arrendadas aos trabalhadores rurais (foreiros), que pagavam os foros (pelo uso da terra) e o campão (um dia de trabalho a mais a serviços dos coronéis). Ressalta-se que as relações entre os fazendeiros e os trabalhadores também eram marcadas por diferentes formas de violência nas condições de trabalho, análogas ao trabalho escravo - práticas extremas de exploração e dominação, baseadas na violência física e/ou simbólica e referidas como formas atuais de escravidão (BRUMER; SANTOS, 2006, p. 62).

Segundo Moacir Palmeira ${ }^{9}$, as ideias cruciais sobre as críticas e estratégias dos movimentos eram fomentadas por Julião, mas os camponeses tinham um potencial incrível de críticas e soluções para os problemas enfrentados. A luta era contra o coronelismo no Brasil, no combate as práticas feudais (pagamento de campão), e a favor da Reforma Agrária e de melhores condições de vida.

As Ligas Camponesas se expandiram no país, juntaram-se ao movimento os foreiros, minifundiários, associações e até mesmo os trabalhadores assalariados que não gozavam de alguns direitos - como, por exemplo, o salário mínimo. O movimento abarcou a maior parte das associações do norte e do nordeste do Brasil, ao todo eram mais de dez mil camponeses associados - o que chamou a atenção da imprensa nacional sendo destacada a frase que marcou o movimento: "Reforma Agrária na Lei ou na marra!’. Em 1961, aconteceu o I Congresso dos Lavradores e Camponeses sem Terra, também conhecido como Congresso Camponês de Belo Horizonte, que foi organizado pela União dos Lavradores e Trabalhadores Agrícolas do Brasil (ULTAB) e financiado pelo governo federal. A mobilização para esse encontro foi uma proposta da I Conferência Nacional dos Lavradores e Trabalhadores Agrícolas, realizada em 1959. Antecederam o encontro de Belo Horizonte vários outros preparatórios, como o I Congresso de Trabalhadores Rurais do Paraná, o II Congresso Camponês de Maringá, a II Conferência de Trabalhadores do Estado do Rio, e outros ${ }^{10}$.

Mais de mil e seiscentos trabalhadores do campo de todo o Brasil se reuniram neste encontro, que foi considerado um marco histórico, sendo o momento em que a campanha pela reforma agrária começou a assumir dimensões nacionais. Após o Congresso Camponês de Belo Horizonte, medidas foram aceleradas como a regulamentação dos sindicatos e o Estatuto do Trabalhador Rural - uma importante conquista na área dos direitos dos trabalhadores rurais.

\footnotetext{
9 Ver no Documentário "Franciso Julião: na lei ou na marra", disponível em: <https://www.youtube.com/watch?v=43n2sfBy0Ho\&t=18s>, acesso em: em 18 de março de 2019.

${ }^{10}$ Ver mais em: <http://www.fgv.br/cpdoc/acervo/dicionarios/verbete-tematico/congresso-dos-lavradores-e-camponesessem-terra-i>, acesso em: 17 de março de 2018.
} 
Apesar da atuação do movimento ter sido "dentro da legalidade", os latifundiários chamavam o movimento de "Ligas de Bandidos". Militares, políticos e fazendeiros discursavam sobre a preocupação de que o Brasil poderia se tornar uma "nova Cuba" ou uma "República Sindicalista". Havia claramente uma disputa ideológica para travar o movimento, que era temido pelos grupos de direita diante da possibilidade de uma revolução no país.

A Ditadura Militar de 1964, após dez anos do início das Ligas Camponesas, agiu prontamente contra o movimento, culminando em assassinatos, prisões, perseguições e no exílio de líderes e membros. Foram episódios de extrema violência e de mortes, sufocando este movimento social e derrubando bruscamente os planos e sonhos dos camponeses. Julião deixou o Brasil e permaneceu exilado no México até o ano de 1979, quando retornou ao país.

Nos meados dos anos 1980 outros exilados retornaram, os movimentos de luta pela Reforma Agrária foram renovados, e no decorrer da década de 1990 essa discussão voltou a ocupar o palco político do país, e "novos movimentos sociais" assumiram essa luta política em distintas regiões do Brasil (BRUMER; SANTOS, 2006).

A mobilização para a conquista da terra passou a ser caracterizada por ocupações e acampamentos. Destacamos, especialmente, a Encruzilhada Natalino que se tornou símbolo da luta de resistência à ditatura militar, em 1981. O envolvimento de centenas de famílias nesta ocupação teve visibilidade nacional, o que mobilizou outros camponeses sem terra, iniciando o processo de consolidação do Movimento dos Trabalhadores Rurais sem Terra (MST). Esta organização não sindical nasceu em 1984, durante o $1^{\circ}$ Encontro Nacional dos Trabalhadores Sem Terra, em Cascavel, no Estado do Paraná. No ano seguinte, 1985, foi realizado o $1^{\circ}$ Congresso Nacional em que foi estabelecida a ocupação de terra como forma de luta ${ }^{11}$.

A pressão social através das ocupações desde o início teve como resposta agressões físicas/simbólicas e homicídios - praticados pelos latifundiários "como recurso extremo para reter a propriedade privada capitalista da terra" (OLIVEIRA, 2001, p. 192). Muitos conflitos no campo foram registrados nestes anos, apontando um crescimento da violência envolvendo "posseiros", "rendeiros", "foreiros"; os estudos agrários revelam dimensões históricas e atuais da violência no campo.

Segundo Brumer e Santos (2006, p. 61): “a conflitualidade social nos campos e florestas configura-se pela violência e pelas lutas sociais, tendo, quase sempre, como motivação principal, as disputas em torno da propriedade e do uso da terra". Estes conflitos, para além dos camponeses, estão

\footnotetext{
11 Ver mais sobre a história do MST, disponível em: 〈http://www.mst.org.br/nossa-historia/84-86>, acesso em: 17 de março de 2018 .
} 
presentes nas histórias de diversas regiões e grupos sociais no Brasil - populações da Amazônia entre índios, seringueiros e colonos; comunidades atingidas por barragens em Minas Gerais e tantos outros (BRUMER; SANTOS, 2006).

Oliveira (2001) apresenta a história da Reforma Agrária apontando as formas de repressão utilizadas por cada Governo brasileiro, em especial, destaca-se o Governo do Fernando Henrique Cardoso (FHC) que embora tenha atendido aos pedidos de regularização fundiária de diversos assentamentos, principalmente na região da Amazônia, teve como estratégia a violência policial e a criminalização dos líderes do MST e de outros movimentos.

Nesse sentido, Rocha e Barbosa Jr. (2018) abordam o tema da criminalização dos movimentos sociais no Brasil como uma forma de governar, um fenômeno inserido em dinâmicas sociais e políticas de controle social. Do ponto de vista normativo, trata-se da consolidação de todo um aparato punitivo para "ordenação" da sociedade brasileira. Segundo estes autores,

Mesmo após o período ditatorial, criações penais de elevado caráter repressivo foram sancionadas e possuem efeitos já sentidos, como a Lei das Organizações Criminosas (Lei 12.580, de 2 de agosto de 2013) e a Lei Antiterrorismo (Lei 13.260, de 16 de março de 2016), além da não revogação da Lei de Segurança Nacional de 1935, criada ainda no período autoritário do Estado Novo (ROCHA; BARBOSA JR., 2018, p. 207)

Trata-se, em síntese, da utilização dos diferentes aparelhos de Estado (Parlamento, Judiciário, Ministério Público, etc.) e seus instrumentos legais para caracterizar como crime as ações das lideranças populares.

Mesmo considerando os expressivos avanços das políticas públicas de segurança alimentar e nutricional no Brasil durante o Governo Lula (SILVA, 2018), e que o ex-presidente sempre teve forte apelo em favor de "causas populares" e do próprio MST; o arranjo político sócio-histórico manteve a criminalização e dominação ante a potência destes movimentos de resistência - marcando o papel ambíguo do Estado.

Rocha e Barbosa Jr. (2018) discutem a questão agrária brasileira explorando os diversos modos pelas quais as ações do Estado "simultaneamente produz conflitos sociais no campo, desqualifica-os e/ou age sobre eles para atenuá-los segundo projetos de dominação". Nesse sentido, os autores destacam que "a ambivalência do Estado no Brasil não demonstra ser algo contraditório, mas sim a ilustração de distintas formas para assegurar interesses e reforçar a autoridade de determinados grupos e instituições" (ROCHA; BARBOSA JR., p. 215). 
Assim, seguindo a proposta do presente trabalho, destacamos como "as novas/ velhas" formas de controle e dominação de caráter colonial mantém não só a estrutura fundiária, a repressão violenta aos que lutam; mas, também, a "imagem negativa" de alguns movimentos sociais perante o restante da sociedade. O MST é exemplo, neste debate, sendo um movimento que se tornou bastante polêmico no Brasil ao longo das últimas três décadas.

Como afirma Oliveira (2001, p. 193): "Se a violência gera a morte, gera também as formas de luta contra a morte. O Movimento dos Trabalhadores Rurais Sem Terra (MST) é produto dessa contradição". Desde sua raiz este movimento luta pela reforma agrária, quando essencialmente a luta é pela vida, por condições de mínimos sociais para sobrevivência, como moradia, alimentação e trabalho - ressalta-se que são direitos garantidos na Constituição Federal/1988, a carta magna dos direitos e deveres fundamentais de toda a população brasileira.

Se por um lado a colonização moderna ampliou sua área de atuação, de outro lado os movimentos sociais aumentaram a pressão social sobre o Estado na luta pela terra, ampliando também as dimensões de sua reivindicação. Ao longo dos seus trinta e poucos anos o MST e outros movimentos têm renovado suas pautas em articulação com movimentos internacionais, como a Via Campesina. Novos temas foram agregados, como a agroecologia e a Soberania Alimentar, ampliando o debate sobre a alimentação e o uso da terra, visando o fortalecimento de modos de produção socialmente justos, culturalmente adequados e ambientalmente prudentes. Temas que marcam a resistência e luta contra-hegêmonica, diante dos imperativos capitalista e dos discursos progressistas do agronegócio.

\section{Considerações finais}

A discussão apresentada neste estudo ressalta um ponto bastante complexo e atual no Brasil: no que tange as disputas entre agronegócio X soberania alimentar nota-se que são crescentes as representações e mobilizações político-ideológicas que inferiorizam os movimentos sociais populares, suas reinvindicações e histórias de lutas, em prol do "progresso" do país.

Isto demonstra a necessidade de superar o ceticismo acadêmico, cultural e político que marginaliza os movimentos sociais a nível global e nacional, bem como suas lutas que demonstram resiliência e são exemplos de que povos e comunidades se mobilizam para enfrentar as inseguranças geradas pelo império alimentar. Os estudos sobre decolonialidade têm contribuído, ainda que timidamente, para a ruptura de ideologias coloniais enraizadas em nossos costumes. 
Dar visibilidade aos movimentos sociais é tocar no assunto, é fortalecer e ampliar o debate sobre as histórias de resistências frente à atitude imperial. No Brasil os movimentos foram marcados por conflitos sangrentos, discriminados e criminalizados.

Os movimentos foram muitas vezes vencidos, mas não sem avanços. $\mathrm{O}$ fato de a alimentação estar incluída no rol dos direitos constitucionais, assim como o pouco que temos de estrutura (na legislação e nos aparatos institucionais) para as políticas públicas de Segurança Alimentar no Brasil, sem dúvida são conquistas dos movimentos sociais.

Diante disso, requer considerar que estas diferentes formas de mobilização e resiliência no campo da segurança alimentar necessitam de visibilidade e da construção de espaços re-localizados para a ampliação do debate, sendo um elemento chave para a construção de alternativas ao desenvolvimento unilateral de caráter economicista, visando sistemas alimentares mais justos.

Assim, alcançando outro ponto importante, a necessidade de incitar o envolvimento comunitário, garantindo a participação social nos espaços da academia e dos serviços públicos para unir a ciência com a sabedoria popular - ou seja, conectar o que a ciência tem avançado sobre a agroecologia e a biotecnologia, com o conhecimento adquirido pela população através do tempo e de experiências atuais no campo da agricultura/alimentação.

\section{Referências}

ALMEIDA JR., A. A ideia de corpo: suas relações com a natureza e os assuntos humanos. In: CAVALCANTI, C. (Org.). Desenvolvimento e Natureza: Estudos para uma sociedade sustentável. Recife: INPSO/FUNDAJ, Ministério da Educação, Governo Federal, 1994. Cap. 8, p. 84- 91.

ANDRADES, T.; GAMINI, R. Revolução verde e a apropriação capitalista. CES Revista, Juíz de Fora, v. 21, p.43 - 56, 2007. Disponível em: <https://www.cesjf.br/revistas/cesrevista/edicoes/2007/revolucao_verde.pdf>. Acesso em: 25 de fevereiro de 2019.

BORRAS, S. La Via Campesina: um movimiento em movimiento. Amsterdã: Transnational Institute, 2004.Disponível em: <https://www.tni.org/files/campesina-s.pdf>. Acesso em: 28 de fevereiro de 2019.

BRASIL, P. O Brasil e a insegurança alimentar global: forças sociais e política externa (20032010). 2013. Dissertação. Mestrado em Relações Internacionais - Instituto de Relações Internacionais, Universidade de Brasília, Brasília. Disponível em: <repositorio.unb.br/bitstream/10482/13878/1/2013_PilarFigueiredoBrasil.pdf>. Acesso em: 05 de fevereiro de 2019. 
BRUMER, A.; SANTOS, J. Estudos agrários no Brasil: modernização, violência e lutas sociais (desenvolvimento e limites da Sociologia Rural no final do século XX). Revista NERA, Presidente Prudente, v. 9, n. 9, p. 49-72, 2006. Disponível em: <www2.fct.unesp.br/nera/revistas/09/Brumer.pdf>. Acesso em: 27 de fevereiro de 2019.

BUAINAIN, A.M.; PIRES, D. Reflexões sobre reforma agrária e questão social no Brasil. Brasília: INCRA. 2003. Disponível em: <www.abda.com.br/texto/antoniobuainain.pdf>. Acesso em: 03 de fevereiro de 2019.

CAPRA, F. O ponto de mutação. A ciência, a sociedade e a cultura emergente. São Paulo, Cultrix, 1981.

CAPRA, F. As conexões ocultas. Ciência para uma vida sustentável. São Paulo: Ed. Cultrix, 2002.

ESCOBAR, A. Sentipensar con la tierra: Las luchas Territoriales y la Dimension Ontologica de las Epistemologias del Sur. Revista de Anropologia Ibero americana. Vol.11, n. 1, P. 11 - 32, 2016. Disponível em:<www.aibr.org/antropologia/netesp/numeros/1101/110102.pdf >

HARVEY, D. O Novo Imperialismo. 2. ed. São Paulo: Loyola, 2003.

HOROCHOVSKI, R.; JUNCKES, I.; SILVA, E.; SILVA, J.; CAMARGO, N. Redes de partidos políticos tecidas por financiadores: um estudo das eleições de 2010 no Brasil. Revista Teoria \& Sociedade. V. $23, \quad$ n. $2, \quad$ p. $49-\quad 78$, 2015. Disponível em: http://bibliotecadigital.tse.jus.br/xmlui/bitstream/handle/bdtse/4563/2015_horochovski_redes_partid os_pol\%C3\%ADticos.pdf?sequence=1\&isAllowed=y>. Acesso em: dezembro de 2017.

KAPP, K. A natureza da economia como um sistema aberto e suas implicações. In: DOPFER, K. (Org.) A Economia do Futuro: Em Busca de um Novo Paradigma. Rio de Janeiro: Zahar, 1979. p. 91-104.

LANDER, E. Ciências sociais: saberes coloniais e eurocêntricos. In: LANDER, E. (org). A colonialidade do saber: eurocentrismo e ciências sociais: perspectivas latino americanas. Buenos Aires: Coleccin SurSur, CLACSO, 2005. Cap. 1, p.8-23. Disponível em: $<$ https://edisciplinas.usp.br/.../colonialidade_do_saber_eurocentrismo_ciencias_sociais.pdf >.

MALDONADO-TORRES, N. Sobre la colonialidade del ser: Contribuiciones al desarrollo de um concepto.In: CASTRO-GÓMEZ, S.; GROSFOGUEL, R. (Ed.). El giro decolonial: reflexiones para una diversidad epistémica más allá del capitalismo global. Bogotá: Siglo del Hombre Editores; Universidad Central, Instituto de Estudios Sociales Contemporáneos y Pontifi cia Universidad Javeriana, Instituto Pensar,2007. Cap. 6, p. $127-167$. Disponível em: <www.unsa.edu.ar/histocat/hamoderna/grosfoguelcastrogomez.pdf>.

MEDEIROS, É.; FONSECA, B. As bancadas da câmara. Agência pública. São Paulo, 2016. Disponível em: http://apublica.org/2016/02/truco-as-bancadas-da-camara/. Acesso em: 10 de marços de 2019.

MOTTA, M.; ESTEVES, C. Ligas Camponesas: história de uma luta (des)conhecida. In: MOTTA, M.; ZARTH, P. (Org.). Formas de resistência camponesa: visibilidade e diversidade de conflitos ao longo da história. Concepções de justiça e resistência nas repúblicas do passado (1930-1960). São Paulo: Unesp, 2009. v. 2. Cap. 11, p. 243-257. 
O GLOBO. De olho em 211 votos do agronegócio, Temer avança na agenda dos ruralistas. Revista Época Negócios. 2017. Disponível em: < http://epocanegocios.globo.com/Brasil/noticia/2017/07/deolho-em-211-votos-do-agronegocio-temer-avanca-na-agenda-dos-ruralistas.html >. Acesso em: $10 \mathrm{de}$ março 2019.

OLIVEIRA, A. A longa marchado campesinato brasileiro: movimentos sociais, conflitos e Reforma Agrária. Estudos Avançados, São Paulo, v. 15, n. 43, p.185- 206, 2001. Disponível em: <www.scielo.br/scielo.php?script=sci_arttext\&pid=S0103-40142001000300015>.

PARANÁ. Política e Sistema de Segurança Alimentar e Nutricional do Estado do Paraná. Secretaria do Estado do Trabalho, Emprego e Promoção Social, Curitiba, 2009.

PLOEG, J. Camponeses e impérios alimentares: lutas por autonomia e sustentabilidade na era da globalização. Trad. Rita Pereira. Porto Alegre: UFRGS, 2008.

ROCHA, P.; BARBOSA JR., R. Criminalizar é governar: uma proposta teórica para a compreensão da criminalização dos movimentos sociais do campo no Brasil. Colombia Internacional, v. 93, p. 205- 232, 2018. Disponível em: 〈www.scielo.org.co/pdf/rci/n93/0121-5612-rci-93-00205.pdf〉.

SACHS, I. Desenvolvimento includente, sustentável, sustentado. Rio de Janeiro: Garamond, 2008.

SERIGATI, F.; POSSAMAI, R.; SEVERO, K. Economia brasileira: o ano de 2018 começa melhor do que o de 2017. Agroanalysis, Rio de Janeiro, v. 37, f. 12, p. 16 - 18, 2017. Disponível em: <bibliotecadigital.fgv.br/ojs/index.php/agroanalysis/article/download/76452/73303>.

SILVA, C. Tecendo a gestão co-participativa rumo à Segurança Alimentar: desafios de uma experiência de pesquisa-ação em Itapoá SC. 2018. Dissertação. Mestrado em Desenvolvimento Territorial Sustentável - Setor Litoral, Universidade Federal do Paraná, Matinhos. Disponível em: <https://acervodigital.ufpr.br/handle/1884/58288>.

VIEIRA, P. Rumo ao desenvolvimento territorial sustentável: esboço de roteiro metodológico participativo. Eisforia. Florianópolis, v.4, n. 4, p. 249-309, 2006. Disponível em: <www.litoral.ufpr.br/portal/wp-content/uploads/2015/.../artigo-paulo-freire-vieira.pdf>.

\section{Documentários:}

Francisco Julião: na lei ou na marra. Documentário. Direção: Fernando Barcellos. Produção: Observatório Fundiário Fluminense/Universidade Federal Fluminense, 2009 (23 min.). Disponível em: <https://www.youtube.com/watch?v=43n2sfBy0Ho\&t=18s >; acesso em: 18 de março de 2019.

Memórias clandestinas. Documentário. Direção: Maria Thereza Azevedo. Produção: Camila Tavares; Maria Thereza Azevedo; Cristiano Ramalho e Vitória Azevedo Fonseca, 2007 (52 min). Disponível em: <https://www.youtube.com/watch?v=R2bi5c9W2r8>, acesso em: 18 de março de 2019.

Artigo recebido em 31/03/2019. Aceito para publicação em 27/05/2019. 